\title{
The Influence of Tillage on Dispersal of Tilletia indica Teliospores from a Concentrated Point Source
}

T. W. Allen and F. Workneh, Texas Agricultural Experiment Station, Bushland 79012-0010; K. C. Steddom, Texas Agricultural Experiment Station, Overton 75684; G. L. Peterson, United States Department of AgricultureAgricultural Research Service, Foreign Disease-Weed Science Research Unit, Fort Detrick, MD 21702-5023; and C. M. Rush, Texas Agricultural Experiment Station, Bushland

\begin{abstract}
Allen, T. W., Workneh, F., Steddom, K. C., Peterson, G. L., and Rush, C. M. 2008. The influence of tillage on dispersal of Tilletia indica teliospores from a concentrated point source. Plant Dis. 92:351-356.

A study was conducted to determine the impact of tillage on dispersal of Tilletia indica teliospores from a concentrated point source in Arizona. The infested source was created using a $300-\mathrm{ml}$ teliospore suspension, containing approximately $9.0 \times 10^{4}$ teliospores $/ \mathrm{ml}$, sprayed onto a 1-by-3-m soil area. Approximately $400 \mathrm{~g}$ of soil was collected before tillage treatments, representing the teliospore baseline, and after each of five disk passes, to an approximate depth of 20 $\mathrm{cm}$, through the infestation source $(n=597)$. Soil samples were collected along three parallel lines extending from the infested area at increments of 1,3 , or $10 \mathrm{~m}$ to a total distance of 10,30 , and $50 \mathrm{~m}$, respectively. Teliospores were recovered from soil samples by a combined sizeselective sieving sucrose-centrifugation technique. Immediately following teliospore infestation, an average of $3.6 \times 10^{3}$ teliospores per $25 \mathrm{~g}$ of soil sample were recovered from the infestation area. Two different trends in recoverable teliospores occurred at 0 - to 10-m sampling distances following five plow passes: either a decrease in the number of teliospores recovered, represented at points 0,1 , and $2 \mathrm{~m}$, or an increase in recoverable teliospores found at points 3 to $10 \mathrm{~m}$. The study was repeated twice for a total of three experiments, and teliospores were recovered to a maximum distance of $24 \mathrm{~m}$. However, the numbers recovered from distances beyond $10 \mathrm{~m}$ were sporadic. Based on data from this research, we conclude that teliospores are not distributed in large quantities to great distances by tillage and, therefore, tillage cannot account for the spatial distribution of teliospores in many infested wheat fields.
\end{abstract}

Additional keywords: Karnal bunt

Karnal bunt (also known as partial bunt) of wheat $(\mathrm{Kb})$, caused by Tilletia indica Mitra (=Neovossia indica (Mitra) Mundk.), is an internationally, economically, and politically important disease of wheat. $T$. indica is currently a zero-tolerance regulated organism in the United States and under importation restriction in more than 40 countries $(15,20)$. The fungus produces teliospores that serve as the primary source of inoculum, and as the survival structure that may survive in soil under field conditions for at least 5 years $(2,14)$. Teliospore introductions into wheat field soils can occur by movement of infested soil, planting infected or infested wheat, movement of air from infested areas, application of infested manure, and on custom harvesting

Corresponding author: C. M. Rush

E-mail: cm-rush@tamu.edu

Current address of T. W. Allen: Delta Research and Extension Center, Mississippi State University, Stoneville.

Accepted for publication 17 October 2007.

doi:10.1094/PDIS-92-3-0351

(C) 2008 The American Phytopathological Society equipment $(3-6,8,9,14,18,19,21)$. However, the initial introduction(s) of T. indica into the United States probably occurred on bunted grain entering from Mexico in the 1980s (5). Karnal bunt first was identified in the United States in 1996 outside of Phoenix, AZ (22) and has since been documented in California and Texas $(3,13,15)$.

Research on the distribution of $\mathrm{Kb}$ in wheat fields $(15,16)$ and distribution of soilborne teliospores $(1,20)$ has been conducted previously. Sawyer et al. (16) reported that $\mathrm{Kb}$ has a random, aggregated pattern in a durum wheat fields in Arizona (see also 15). Allen et al. (1) reported that the spatial teliospore distribution in Texas wheat fields was either aggregated, discontinuous, or random. Teliospores were reported to be widely distributed in eight bunted-kernel-positive wheat fields surveyed in 2002 in two geographically separate regulated regions in Texas. Additionally, a recent study has discussed the impact of tillage on disease development in wheat rotations in India (17). Even though $\mathrm{Kb}$ has been in the United States for more than 10 years, no studies have been conducted to determine factors that impact dispersal of the pathogen in field soil.
Because teliospores are widespread in infested Texas wheat fields, a study was initiated to determine dispersal dynamics of $T$. indica teliospores from an infested point source by tillage.

\section{MATERIALS AND METHODS}

Experimental field. An 8-ha wheat field located approximately $55 \mathrm{~km}$ south of Phoenix, AZ was used for this study. The field had a prior history of $\mathrm{Kb}$, testing bunted kernel positive in 2001. This research was conducted in Arizona because it is one of the few locations in the United States where teliospores can be introduced into the soil for research purposes. Furthermore, all research and movement of soil was conducted under the authorization of the Arizona Department of Agriculture, United States Department of AgricultureAnimal and Plant Health Inspection Services (USDA-APHIS), and Texas Department of Agriculture by permits obtained prior to initiation of this study.

Creation of spore suspension. Teliospores originally obtained from naturally bunted kernels were plated onto $1.5 \%$ water agar and allowed to incubate for 21 to 28 days at $17^{\circ} \mathrm{C}$ with a 12-h light:dark photoperiod. Secondary sporidia were washed from culture plates by flooding the plate with approximately $5 \mathrm{ml}$ of sterile distilled water (SDW) and sporidia were dislodged by gently scraping them from the plate using a small $(0.6-\mathrm{cm})$ artist's brush. This suspension then was poured into a second plate and the process was repeated for five plates. The final suspension was poured into a sterilized $100-\mathrm{ml}$ collection beaker. The spore density was determined using a hemacytometer and adjusted to a final concentration of $1 \times 10^{4}$ sporidia/ml using SDW.

Growth of Kb-infected wheat, teliospore extraction from infected wheat seed, and infestation of point source. Spring wheat cv. Cavalier was sown in late November 2003. Three separate $1.2-\mathrm{m}^{2}$ plots of wheat were used for inoculation. All wheat plants within each plot were inoculated at the boot stage (Feekes stage 10) with $1 \mathrm{ml}$ of the spore suspension, using a Cornwall repeating syringe. Individual wheat heads were inoculated approximately $3 \mathrm{~h}$ before sundown to limit exposure to high temperatures at time of boot inoculation. 
Wheat heads were hand harvested at the end of the season (approximately the last week in May 2004) and returned to the USDA-Agricultural Research Service (ARS) Foreign Disease-Weed Science Research Unit, in Fort Detrick, MD. Wheat heads were stored in paper bags at approximately $22^{\circ} \mathrm{C}$ until threshing. Individual wheat heads were hand threshed by rubbing heads between hands to extract bunted kernels in the BL-3 containment facility at Fort Detrick, and bunted kernels were removed.

Teliospores were extracted by placing bunted kernels in a 100- $\mu$ m stainless steel mesh sieve and lightly pressing and rolling seeds using a $2.5-\mathrm{cm}$ stiff bristle paint brush to rupture sori. Teliospores were collected in a pan below the sieve. This process was continued until $3 \mathrm{~g}$ of teliospores were collected. A teliospore suspension was created by adding $1 \mathrm{~g}$ of teliospores, containing approximately $2.7 \times 10^{7}$ teliospores, to $300 \mathrm{ml}$ of SDW, representing a final concentration of $9.0 \times 10^{4}$ teliospores $/ \mathrm{ml}$. The resultant teliospore suspension was sprayed onto a 1-by-3-m area of soil using a handheld pump sprayer in November 2004.

Experimental design, tillage, and soil sampling. To monitor spread of teliospores from the infested point source, soil samples were collected along three parallel lines, spaced approximately $0.75 \mathrm{~m}$ apart, extending from the infested area (Fig. 1). The soil type was a clay loam with a $\mathrm{pH}$ of 7.4 and $2.2 \%$ organic matter. Eleven soil samples were collected along each line at either 1-, 3-, or 5-m intervals to a maximum distance of 10,30 , and $50 \mathrm{~m}$, respectively, and included the infestation source (point zero). Soil samples were collected from each distance prior to teliospore infestation or tillage to establish the telio-

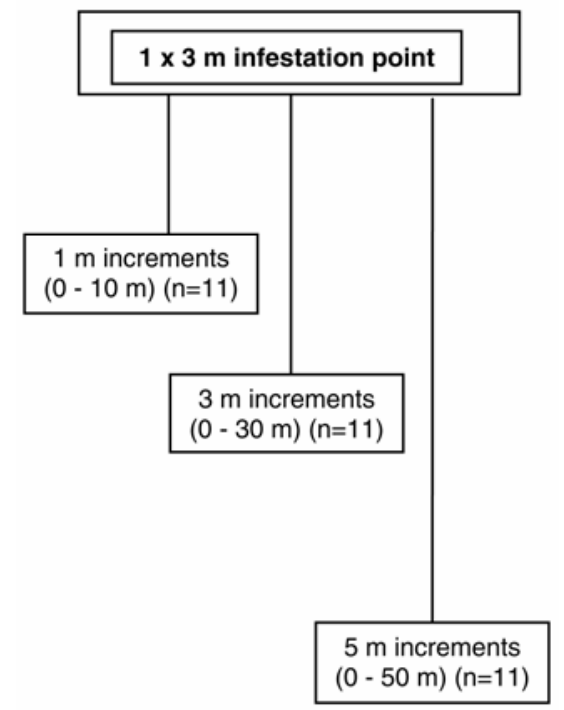

Fig. 1. Map of sampling regime used for each sampling interval of either 1-, 3-, or 10-m increments beyond the point of teliospore infestation, labeled as point source. spore baseline, and immediately following teliospore infestation of the source area. Each individual soil sample, which consisted of three scoops taken with a handheld shovel to a depth of $5 \mathrm{~cm}$, represented approximately $400 \mathrm{~g}$ of soil. Tillage was conducted with a John Deere 355 offset disk plow (John Deere \& Company, Moline, IL), $4.6 \mathrm{~m}$ wide, attached to a John Deere 7920 tractor and pulled at $9.0 \mathrm{~km} / \mathrm{h}$ through the infestation source. Each disk measured $40.6 \mathrm{~cm}$ and reached an approximate depth of $20 \mathrm{~cm}$. The disk passed over the infested area five times and, after each pass, the tractor returned to the infested area so that tillage was conducted in one continuous direction. After each successive plow pass, soil samples were collected from each measured distance $(n=$ 165). Soil samples were brought to the Texas Agricultural Experiment Station Karnal Bunt Quarantine Lab in Bushland, TX for further processing. The experiment was repeated two additional times on the same day, each at a separate location, approximately $200 \mathrm{~m}$ apart, in the field.

Soil preparation and extraction of teliospores. Soil samples were air dried in a type IIA biological hood for 3 to 5 days, and crushed with a rolling pin to separate large clumps. Soil in each individual sample bag was thoroughly homogenized and a 25-g aliquot was removed and placed into a 50-ml polystyrene screw-cap centrifuge tube. Sample tubes were stored at room temperature (approximately $22^{\circ} \mathrm{C}$ ) until processing.

Teliospores were extracted using the method described by Allen et al. (1). Briefly, a 25-g aliquot of soil from each measured sample point was hydrated overnight at room temperature with $25 \mathrm{ml}$ of a $0.1 \%$ Tween 20 (Acros Organics, Fair Lawn, NJ) solution in a 50-ml centrifuge tube. Following hydration, samples were vigorously vortexed for $10 \mathrm{~s}$ (setting no. 9 , Vortex Genie; Scientific Industries, Bohemia, NY) and poured into a $600-\mathrm{ml}$ beaker containing a magnetic stir bar. Two drops of Tween 20 were added and the suspension was rapidly stirred for $5 \mathrm{~min}$. The contents of the beaker were poured onto a stacked $20-\mu \mathrm{m}$ bottom and 53- $\mu \mathrm{m}$ top sieve pair. The top sieve then was placed over a second $20-\mu \mathrm{m}$ sieve and the soil suspension was rinsed through the sieve with the remaining contents of the beaker and thoroughly rinsed with approximately 5 to 7 liters of tap water. The contents of the first $20-\mu \mathrm{m}$ bottom sieve were rinsed into the second $20-\mu \mathrm{m}$ sieve and the soil fraction was thoroughly rinsed until the water draining through the bottom of the sieve was clear. The remaining contents on the sieve were washed back into the $50-\mathrm{ml}$ centrifuge tube and centrifuged for $5 \mathrm{~min}$ $(2,500 \times g)$. The supernatant was poured off and $25 \mathrm{ml}$ of a $1.6 \mathrm{M}$ sucrose solution (800 $\mathrm{g}$ of granulated sugar in 1 liter of reverse osmosis $\mathrm{H}_{2} \mathrm{O}$ ) was added to the centrifuge tube. The suspension was vortexed for $10 \mathrm{~s}$ (setting number 9) and centrifuged for $1 \mathrm{~min}(180 \times g)$, and the supernatant was poured through a $20-\mu \mathrm{m}$ mesh sieve. The sucrose procedure was repeated an additional four times. The contents of the 20- $\mu \mathrm{m}$ sieve were rinsed with approximately 1 liter of tap water, washed into a $15-\mathrm{ml}$ centrifuge tube, and centrifuged for $5 \min (2,500 \times g)$; then, the supernatant was poured off and the pellet was resuspended in $700 \mu \mathrm{l}$ of Shear's solution (12). Teliospores were counted by transferring the suspension to a SedgwickRafter (Kahl Scientific Instrument Corporation, El Cajon, CA) counting chamber and enumerating the total number of teliospores microscopically at $\times 100$ or $\times 400$ as necessary using darkfield microscopy. Intact teliospores with the correct size, a diameter of 22 to $47 \mu \mathrm{m}$ (10), and exhibiting the correct ornamentation (7) were counted.

Statistical analyses. Baseline teliospore numbers from the separate experiments were subtracted from each measured, posttillage teliospore count $(n=33$ per experiment). To determine whether there were significant differences between experiments, an analysis of variance was conducted using SAS (version 9.1; SAS Institute, Cary, NC). Confidence limits were calculated and used to determine the number of teliospores present after tillage treatments for distances beyond $10 \mathrm{~m}, 12$ $\mathrm{m}$ to $50 \mathrm{~m}$, that corresponded to the 3 - and 5 -m increments. The spore numbers within confidence limits were considered part of the background contamination. Logtransformed teliospore count data were analyzed from each point beyond the infestation source using linear and nonlinear regression techniques. To correlate the number of plow passes with the number of spores recovered from each sample point, the best relationship was selected, based on coefficients of determination $\left(R^{2}\right)$ using SAS. GS $^{+}$(version 7; Gamma Design Software, Plainwell, MI) was used to create contour maps and show teliospore distribution following each plow pass.

\section{RESULTS}

In the three experiments, data collected following plow passes from each sampling point beyond the infested point did not differ significantly $(P=0.16)$. Therefore, data for individual experiments were combined for analysis. All teliospore numbers are presented as the number recovered from 25 -g soil samples.

Baseline teliospore numbers for the three experiments ( $n=33$ for each experiment) ranged from 0 to 13 teliospores, with an average of $2.2 \pm 2.8$ teliospores (experiment 1: $0.78 \pm 0.97$, experiment 2: $1.06 \pm 1.02$, and experiment 3: $4.75 \pm$ 3.48). Immediately following teliospore infestation (and prior to any plow pass), an average of $3.6 \times 10^{3}$ teliospores were re- 
covered from the three infestation sources. Following a single plow pass, 464 teliospores were recovered from the infestation point (Fig. 2A). This represents an $87 \%$ reduction in the number of recoverable teliospores in the top $5 \mathrm{~cm}$ of soil at the infestation point. After one plow pass, the maximum number of teliospores recovered, 753, was $1 \mathrm{~m}$ beyond the infestation source. Following each successive plow pass, the maximum number of teliospores was recovered at greater distances from the infestation point (Fig. 2A). However, the maximum number of recovered teliospores after two and three plow passes was detected $2 \mathrm{~m}$ beyond the infestation point whereas the maximum number after four plow passes was found at $3 \mathrm{~m}$. After five plow passes, the maximum number of teliospores was recovered at $4 \mathrm{~m}$. Contour

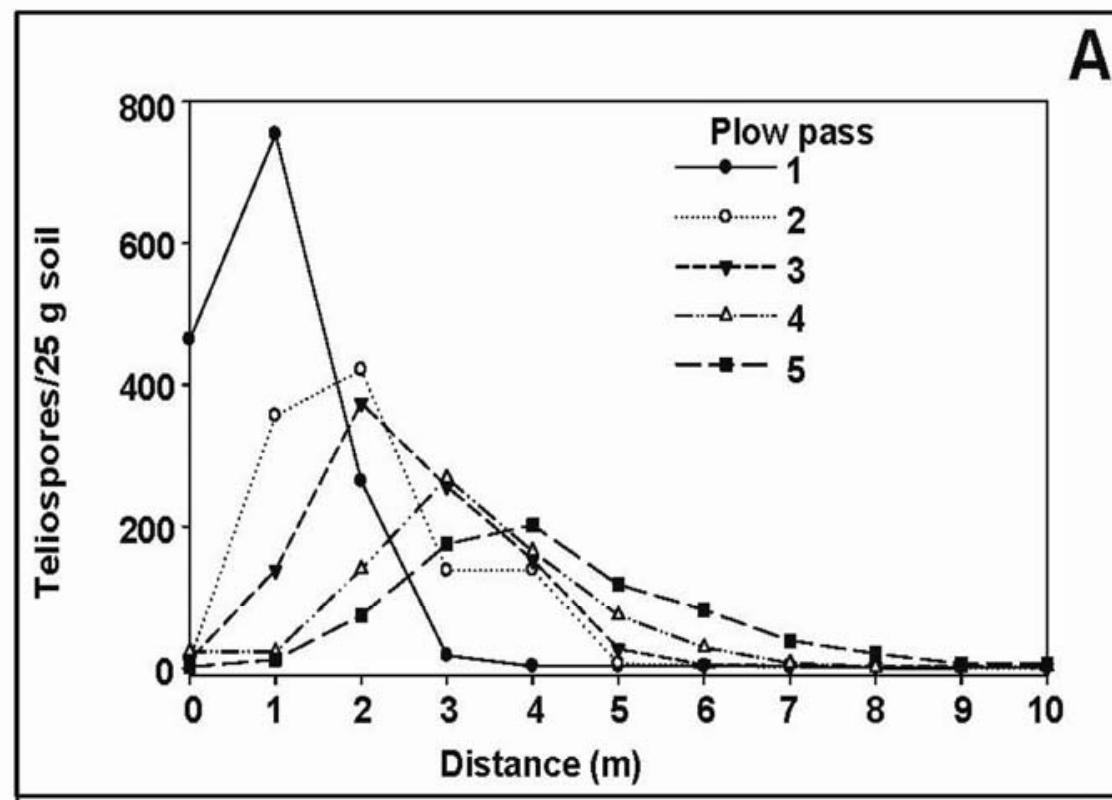

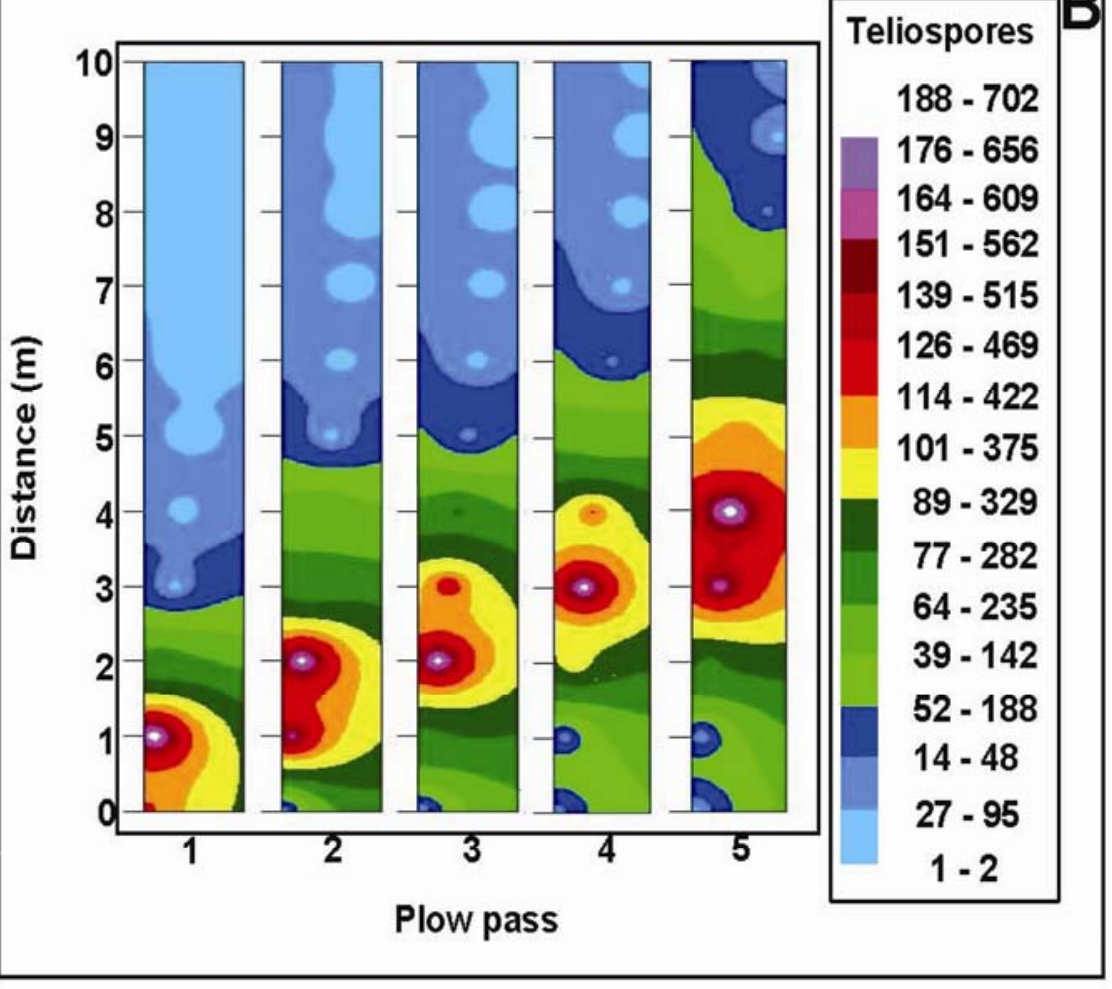

Fig. 2. A, Data for the 0- to $10-\mathrm{m}$ sample points after each of five disk passes through the infestation point (point 0 ). Data are presented for the 0- to 10-m measurements because teliospores were not recovered with increasing frequency beyond $10 \mathrm{~m}$ after five disk passes. Because there were no statistical differences between the three experiments, data were combined. B, Data presented for 0 to $10 \mathrm{~m}$ from the point of teliospore infestation as a contour map for each of the five plow passes. Contour maps are presented to show the distribution of teliospores beyond the point of infestation following each successive plow pass through the infestation point. maps (Fig. 2B) of teliospore dispersal from the infestation point and 1 to $10 \mathrm{~m}$ beyond, following each successive plow pass, are presented to show the movement of a teliospore mass (or aggregate). Each contour map shows the teliospore maximum moving a greater distance from the infestation point following successive plow passes, and a general lack of long-distance teliospore dispersal for large numbers of teliospores. Teliospores were greatly diluted in the soil and not dispersed over long distances.

Data for teliospore numbers at each distance increment, 0 to $10 \mathrm{~m}$, are presented as log-transformed teliospore numbers from each $25-\mathrm{g}$ soil aliquot and represent the number of teliospores recovered for that specific distance following each successive plow pass (Fig. 3). Data for points beyond $10 \mathrm{~m}(12$ to $50 \mathrm{~m})$ are not presented. In short, teliospores additionally were recovered from $12,15,18$, and $24 \mathrm{~m}$ beyond the infestation point in the $3-\mathrm{m}$ sampling set, but the number of spores was low (0 to 5 teliospores) and sporadic following successive plow passes. Teliospores also were recovered from the $20-\mathrm{m}$ sampling point in the 5-m increment sampling set, but the numbers of teliospores varied between 2 after two plow passes, 5 after three passes, and 4 after four passes. In some cases, the number of teliospores recovered from the 3- and 5-m increment sampling points fell within the range of background teliospores, collected prior to infestation and tillage treatments. In general, data from each of the 0 - to $10-\mathrm{m}$ points was best described by quadratic polynomial regression models. All regression models were significant. The teliospore numbers from the infestation point source, and measured distances beyond the infestation point, 1 to $10 \mathrm{~m}$, following each successive plow pass can be classified into three categories: (i) teliospore numbers

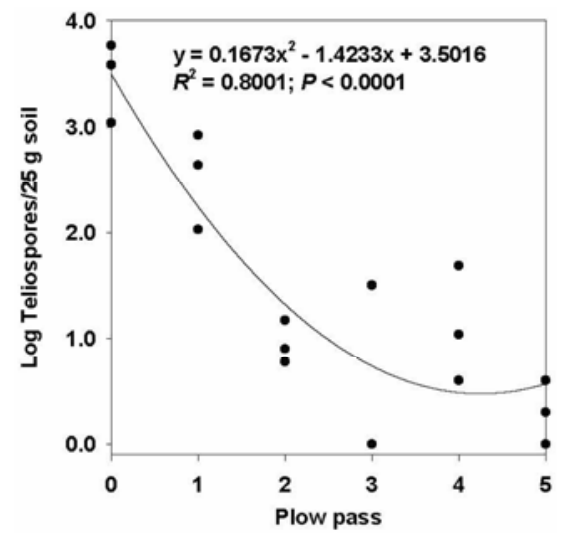

Fig. 3. Scatter plot of log-transformed teliospore counts from the infestation point. Data represent the number of teliospores present immediately following infestation (plow pass 0 ) and following each of five plow passes through the infestation point. Data for all three experiments are presented; therefore, for each plow pass there are three data points $(n=15)$. 
decreasing (Figs. 3 and 4A and B), (ii) teliospore numbers increasing followed by a slight decrease (Fig. 4C and D), and (iii) teliospore numbers increasing (Fig. 4E-J). Teliospore numbers significantly decreased at points 0 (infestation), 1 , and $2 \mathrm{~m}$ following each successive plow pass. At the infestation point source, there was a $99.9 \%$ decrease in recoverable teliospores between the number of spores present immediately after infestation, $3.6 \times 10^{3}$ teliospores, and those after the fifth plow pass (Fig. 3). A significant, 98.4\% $(P<0.0001)$ decrease in recoverable teliospores also occurred $1 \mathrm{~m}$ beyond the infestation point, and a $72.0 \%$ decrease between one and five plow passes occurred $2 \mathrm{~m}$ beyond the infestation source (Fig. 4A and B). Increasing numbers of recoverable teliospores occurred at 3 and $4 \mathrm{~m}$ beyond the infestation point (Fig. 4C and D). Even though teliospore numbers decreased at 3 and $4 \mathrm{~m}$ following the fourth plow pass, there was still a large increase in the number of teliospores between the first and fifth plow pass. Overall increases of 90.8 and $99.0 \%$ in teliospore numbers occurred at 3 and 4 $\mathrm{m}$ beyond the infestation point, respectively. Teliospore numbers increased at points 5 to $10 \mathrm{~m}$ beyond the infestation point after each plow pass. Following a single plow pass, only 1 teliospore was found at $5 \mathrm{~m}$. After the fifth plow pass, 116 teliospores, an increase of $98.3 \%$, were found at the 5-m sampling point (Fig. 4E). A similar percent increase and number of teliospores were found $6 \mathrm{~m}$ beyond the infestation point between one and five plow passes (Fig. 4F). Even though a greater number of teliospores were found 7 $\mathrm{m}$ beyond the infestation point after five plow passes (71 teliospores), a greater percent increase, 94.7\%, occurred at $8 \mathrm{~m}$ (Fig. $4 \mathrm{G}$ and $\mathrm{H}$ ). Low numbers of teliospores were found at both the 9- and 10-m sampling points after the fifth plow pass ( 5 and 4 teliospores, respectively). However, this was a large increase from the approximately 0 teliospores detected at each point after a single plow pass (Fig. 4I and J).

\section{DISCUSSION}

This study was designed to monitor the dispersal of $T$. indica teliospores from an infested 1-by-3-m point source. Extreme care was taken to thoroughly wash individual soil samples. The specific extraction methods used previously have been reported to have an $18 \%$ extraction efficiency for a similar, loam type soil (1). Previous methods, reported by Stein et al. (20), resulted in a $13 \%$ extraction efficiency for a loam soil.

The distribution of bunted kernel incidence in Arizona durum wheat fields $(15,16)$ positive for bunted kernels based on survey samples (bunted kernel positive), and the distribution of soilborne teliospores in bunted-kernel-positive durum and winter wheat fields in Arizona and Texas, respectively (1; T. W. Allen, unpublished data), has been determined previously. However, research has not been conducted to investigate the possible mechanisms of teliospore distribution in soil under field conditions. In the current study, the infestation point was intended to represent a large teliospore introduction from a number of bunted kernels dropped into the soil during harvest or an introduction of teliospore-infested manure from grazing cattle. Even though soil samples were collected to a maximum distance of 10,30 , and $50 \mathrm{~m}$ for each of the three sampling increments, respectively, teliospores were not recovered with high frequency ( $>18$ teliospores per 25 -g soil sample) $8 \mathrm{~m}$ beyond the infestation point following five plow passes. Additionally, low numbers of teliospores were recovered from the 9- and 10-m distances (on average, $<5$ teliospores) and 12, 15, 18, 20, and $24 \mathrm{~m}$ beyond the infestation source $(<5$ teliospores) but in variable quantities and not with increasing consistency following successive plow passes. In fact, based on a contour map of the 0 - to $10-\mathrm{m}$ sampling area, following each successive tillage treatment, an increasing number of teliospores were recovered from each successive sampling distance beyond the infestation point. In general, teliospores were not evenly distributed throughout the sample points and tended to stay in highly recoverable quantities, relatively short distances $(<5$ $\mathrm{m})$ from the infestation point. This suggests that although tillage appears to distribute and dilute teliospores over a short distance, tillage practices alone cannot explain the widespread teliospore distribution from infested wheat fields in Texas.

Previous research in Arizona and Texas bunted-kernel-positive wheat fields has revealed high quantities of soilborne teliospores (1; T. W. Allen, unpublished data). A 2002 grid survey of eight bunted-kernelpositive Texas wheat fields (1) recovered more than 1,000 teliospores per 25 -g soil sample from two sample points. This sampling procedure divided wheat fields into either 60 or 72 sample points spaced 10 or $60 \mathrm{~m}$ apart, and fields ranged from 0.4 to 24 ha in size. In all, 540 soil samples were collected and over $70 \%$ contained one or more teliospores. Bunted-kernel-positive wheat fields first were discovered in Texas in 1997 and identified again in 2001 and 2002. Six of the sampled wheat fields were identified as bunted kernel positive in 2001 while each of the two remaining fields tested positive in 1997 or in both 1997 and 2001, respectively. However, due to the widespread distribution of teliospores in several wheat fields that tested bunted kernel positive only once, the authors believe that $T$. indica teliospores potentially were introduced on more than one occasion. Consequently, this probably occurred prior to 1997 because a strict quarantine was implemented following the identifica- tion of $\mathrm{Kb}$ in Texas. In the current study, five disk passes did not disperse large recoverable quantities of teliospores further than $8 \mathrm{~m}$. This is contrary to the results of a previous study (1) that reported high numbers of teliospores recovered from grid points separated by $10 \mathrm{~m}$. In Texas, most wheat producers use a disk plow for seedbed preparation and average three tillage operations a year. Based on the results of this research, disking could not have distributed teliospores over great distances, or entire fields, in a single year. For example, teliospores were recovered from every grid point in two Texas wheat fields. Both fields were of at least $120 \mathrm{~m}$ in length. If a massive teliospore introduction occurred at a given point (similar to our point source), and the spores were distributed in only a single direction, by factoring in time, it would have taken approximately 15 years for teliospores to be spread the entire 120$\mathrm{m}$ distance. This is based on three tillage events per year and a rough estimate of 8 $\mathrm{m}$ of distribution every five plow passes. It is more likely that teliospores were introduced into the soil in more than one event, rather than a single introduction that was spread across the field over time. Because producers routinely keep some harvested grain as a seed source, bunted kernels could have been planted in successive years, resulting in the creation of a more uniform distribution. The estimated number of teliospores contained in a single bunted kernel range from $1.0 \times 10^{6}$ to $1.4 \times$ $10^{6}$ (11). Moreover, tillage can spread teliospores over short distances whereas infected seed can spread teliospores over both short and long distances. Wind is another possible method of dispersing teliospores over short and long distances. However, only one such experiment has considered teliospore movement into the atmosphere as a result of burning wheat stubble (5). Alternatively, a single massive infestation that was spread evenly across the field could have occurred, such as planting heavily infected or infested seed or spreading infested manure. Manure is not used as a source of fertilizer by Texas producers. However, some fields were grazed by cattle. No direct correlation between disease incidence and grazed or ungrazed wheat fields has been made in the regulated regions of Texas.

Based on preliminary findings from bunted-kernel-positive fields in Texas, it was believed that tillage played a role in the overall distribution of teliospores in field soil. Teliospore numbers ranging from 3 to 121 and 1 to 1,305 have been recovered from two Texas wheat fields (1) and teliospore numbers from a field in Arizona ranging from 6 to 1,000 (T. W. Allen, unpublished data) also have been recovered. Even with five disk passes, sample points with over 1,000 teliospores were not produced beyond the infestation point. This was quite unexpected given the 
large number of teliospores (approximately $2.7 \times 10^{7}$ ) used for the initial infestation. The results of this research allow us to speculate on the method of initial teliospore introductions. Wide teliospore distribution suggests that teliospore introduc- tions did not occur at a single location within a field. However, because the infestation point contained a greater number of teliospores than the estimate from a single bunted kernel, and sample points containing greater than 1,000 teliospores were not recovered, it stands to reason that more than one introduction event, or a single, massive uniform introduction, initially occurred in individual Texas wheat fields.

Data from this project could be used to model the time required for a teliospore

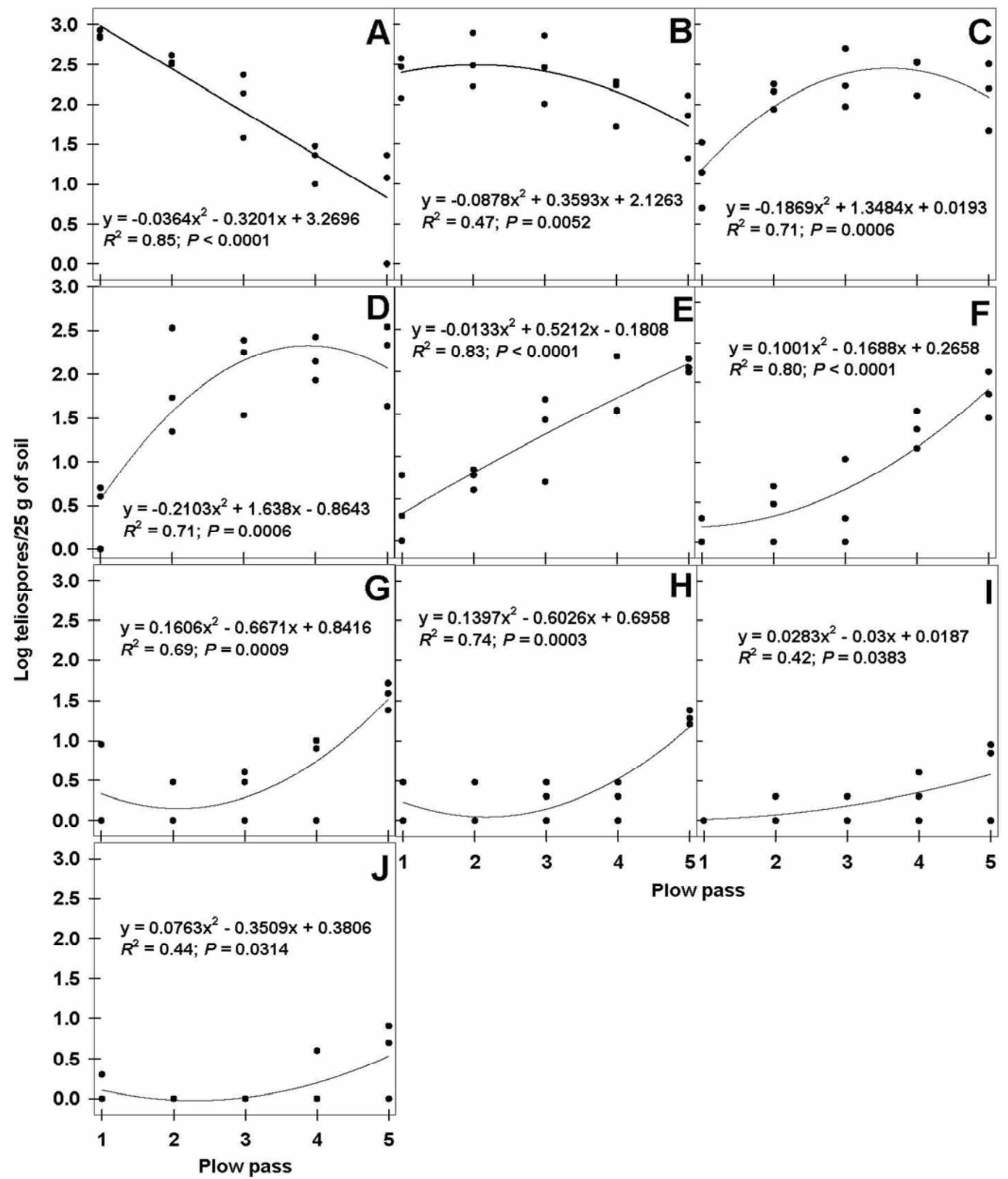

Fig. 4. Scatter plots of log-transformed teliospore counts from beyond the infestation point for A, 1, B, 2, C, 3, D, 4, E, 5, F, 6, G, 7, H, 8, I, 9, and J, $10 \mathrm{~m}$ beyond the infestation point. Each scatter point represents the teliospore count from a single experiment from that distance after either one, two, three, four, or five plow passes ( $n=15$ points per figure). 
infestation source to be dispersed by tillage over a given distance. Such information would be valuable from a regulatory and epidemiological perspective. However, because sporidia compose the actual infecting propagules of $T$. indica, it is clear that a better understanding of the epidemiological factors that impact sporidial generation, survival, distribution, and infection is needed.

\section{ACKNOWLEDGMENTS}

This research was conducted under a specific cooperative agreement between Texas A\&M University and USDA-ARS under project number 5430-21000-005-00D. We thank C. Childers and D. Jones for field assistance; and B. Annen, D. Harvey, and H. W. Maples for technical assistance.

\section{LITERATURE CITED}

1. Allen, T. W., Maples, H. W., Workneh, F., Stein, J. M., and Rush, C. M. 2008. Distribution and recovery of Tilletia indica teliospores from regulated wheat fields in Texas. Plant Dis. 92:344-350.

2. Bonde, M. R., Nester, S. E., Olsen, M. W., and Berner, D. K. 2004. Survival of teliospores of Tilletia indica in Arizona field soils. Plant Dis. 88:804-810.

3. Bonde, M. R., Peterson, G. L., Schaad, N. W., and Smilanick, J. L. 1997. Karnal bunt of wheat. Plant Dis. 81:1370-1377.

4. Bonde, M. R., Prescott, J. M., Matsumoto, T. T., and Peterson, G. L. 1987. Possible dissemination of teliospores of Tilletia indica by the practice of burning wheat stubble. (Abstr.) Phytopathology 77:639.
5. Boratynski, T. N., Matsumoto, T. T., and Bonde, M. R. 1985. Interceptions of Tilletia indica at the California-Mexico border in Mexican railroad boxcars. (Abstr.) Phytopathology 75:1339.

6. Carris, L. M., Castlebury, L. A., and Goates, B. J. 2006. Nonsystemic bunt fungi-Tilletia indica and T. horrida: a review of history, systematics, and biology. Annu. Rev. Phytopathol. 44:113-133.

7. Castlebury, L. A. 1998. Morphological characterization of Tilletia indica and similar fungi. Pages 97-105 in: Bunts and Smuts of Wheat: An International Symposium, Raleigh, NC.

8. Datnoff, L. E., Bonde, M. R., and Royer, M. H. 1986. A technique for quantifying Tilletia indica teliospores in soil. (Abstr.) Phytopathology $76: 1144$.

9. Datnoff, L. E., Royer, M. H., Bonde, M. R., and Prescott, J. M. 1988. A quantitative method for estimation of teliospores of Tilletia indica in soil. Plant Dis. 72:209-212.

10. Duran, R. 1987. Ustalaginales of Mexico, Taxonomy, Symptomology, Spore Germination, and Basidial Cytology. Ruben Duran, Pullman, WA.

11. Garrett, K. A., and Bowden, R. L. 2002. An allee effect reduces the invasive potential of Tilletia indica. Phytopathology 92:1152-1159.

12. Graham, S. 1959. The effects of various reagents, mounting media, and dyes on the teliospore walls of Tilletia controversa. Mycologia 51:477-491.

13. Holmes, G. J., Jackson, L. F., and Perring, T. M. 1997. Imperial Valley conditions limit Karnal bunt in wheat. Calif. Agric. 51:29-33.

14. Joshi, L. M., Singh, D. V., Srivastava, K. D., and Wilcoxson, R. D. 1983. Karnal bunt: A minor disease that is now a threat of wheat. Bot. Rev. 49:309-330.

15. Rush, C. M., Stein, J. M., Bowden, R. L., Riemenschneider, R., Boratynski, T., and Royer, M. H. 2005. Status of Karnal bunt of wheat in the United States 1996 to 2004. Plant Dis. 89:212-223.

16. Sawyer, A. J., Huettel, R. N., and Meyer, R. J. 1997. Within-field spatial distribution of Tilletia indica (Karnal bunt): implications for detection surveys. (Abstr) Phytopathology 87:S85.

17. Sharma, A. K., Babu, K. S., Sharma, R. K, and Kumar, K. 2007. Effect of tillage practices on Tilletia indica Mitra (Karnal bunt disease of wheat) in a rice-wheat rotation of the Indo-Gangetic Plains. Crop Prot. 26:818821.

18. Smilanick, J. L, Dupler, M., Goates, B. J., Hoffman, J. A., Clark, D., and Dobson, D. 1986. Germination of teliospores of Karnal, dwarf, and common bunt fungi after ingestion by animals. Plant Dis. 70:242-244.

19. Smilanick, J. L., Prescott, J. M., Hoffman, J. A., Secrest, L. R., and Weise, K. 1989. Environmental effects on survival and growth of secondary sporidia and teliospores of Tilletia indica. Crop Prot. 8:86-90.

20. Stein, J. M., Maples, H. W., and Rush, C. M. 2005. Epidemiology of Tilletia indica teliospores in regulated wheat fields in Texas. Plant Dis. 89:828-833.

21. Warham, E.J. 1986. Karnal bunt disease of wheat: a literature review. Trop. Pest Manage. 32:229-242.

22. Ykema, R. E., Floyd, J. P., Palm, M. E., and Peterson, G. L. 1996. First report of Karnal bunt of wheat in the United States. Plant Dis. 80:1207. 